\title{
الوسائط الثقافية في رياض الأطفال
}

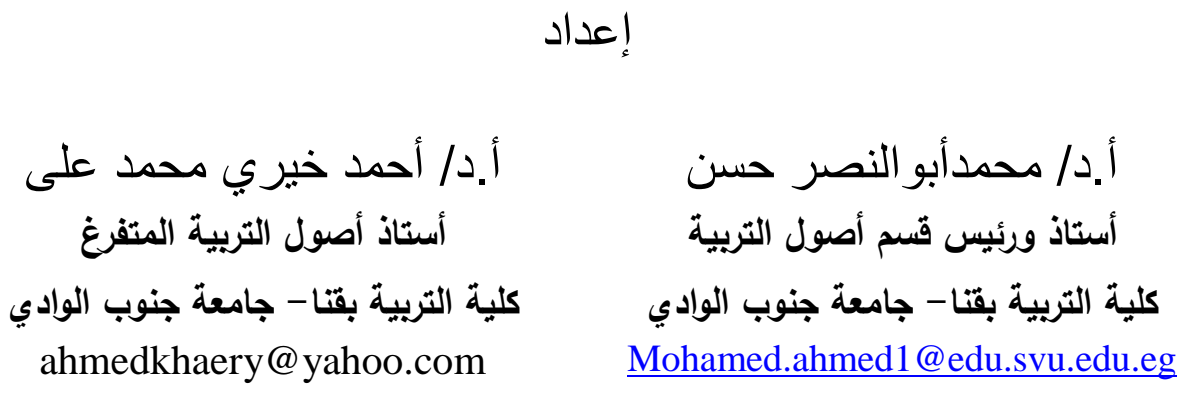

$$
\text { كلية التربية بقتا ماجتير - جامعة جني قدم أصول التربية حفوضة الوادية }
$$

NeamaAli@edu.svu.edu.eg 


\begin{tabular}{|c|c|c|}
\hline \multicolumn{3}{|c|}{ الوسائط الثقافية في رياض الأطفال } \\
\hline أ/ نعمة علي محمد حفوضة & أ.د/ أحمد خيري محمد & أ.د/ محمد أبو النصر حسن \\
\hline
\end{tabular}

\section{الوسائط الثقافية في رياض الأطفال}

$$
\text { إعداد }
$$

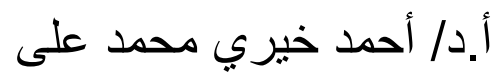

$$
\begin{aligned}
& \text { أ.د/ محمدأبو النصر حسن } \\
& \text { أستاذ أصول التربية المتفرغ } \\
& \text { أستاذ ورئيس قسم أصول التربية } \\
& \text { كلية التربية بقتا - جامعة جنوب الوادي } \\
& \text { كلية التربية بقتا- جامعة جنوب الوادي }
\end{aligned}
$$

$$
\text { كلية التربية بقتا ماجتير - جامعة علي محمد أصول التربية جنوضة الوادية }
$$

NeamaAli@edu.svu.edu.eg

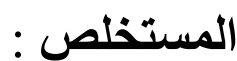

هدفت الدراسة الحالية إلى التعرف على الوسائط الثقافية التي يمكن من خلالها تثقيف طفل الروضة ، ولتحقيق هذا الهدف تتاولت الدراسة أربع أنواع من هذه الوسائط والتي تتمنل في: الوسائط الثقافية المقروءة ومنها الكتاب والمجلة ،وهو نوع بستخدم المطالعة كوسيلة اتصال وتأثير بأن الرسالة فيه تبقى ثابتة يمكن الرجوع إليها ، والوسائط الثقافية المسموعة كالإذاعة والاسطوانات ،والوسائط المرئية كالتلفاز والمسرح والسينما والفيديو ،وهي تعتمد الصوت والصورة في نقاها للثقافة ،وتمتاز بدرجة عالية من الفاعلية والتأثير لأنها تتوجه إلى حاستي السمع والبصر

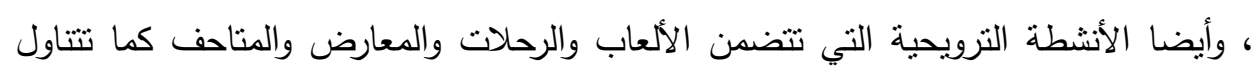
الأنشطة التي يمارسها الطفل في مراكز التعلم داخل قاعات الروضة. الكلمات المفتاحية: الوسائط الثقافية - رياض الأطفال. 


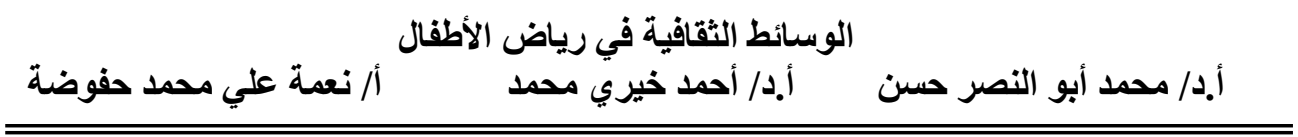

\section{Cultural Media in Kindergartens}

Prof.Dr. Mohamed EI Nasr Hassan

Education Assets Department

Faculty of Education in Qena

South Valley University

Mohamed.ahmed1@edu.svu.edu.eg
Dr. Ahmed Khairi Mohamed

Education Assets Department

Faculty of Education in Qena

South Valley University

ahmedkhaery@yahoo.com

\section{Neama Ali Mohamed Haffouda}

Master Researcher Education Assets Department

Faculty of Education in Qena

South Valley University

NeamaAli@edu.svu.edu.eg

\section{Abstract :}

The aim of this study is to identify the cultural media through which the kindergarten child can be educated. To achieve this goal, the study dealt with four types of media, namely: the cultural media, including the book and the magazine, The media, such as television, theater, cinema and video, rely on sound and image in their transmission of culture, and have a high degree of effectiveness and influence because they are directed to the senses of hearing and sight, Recreational activitiesthat include games, trips, exhibitions and museums also address the activities practiced by the child in the learning centers within the halls of kindergarten.

Keywords: Cultural Media - Kindergarten . 
لقد تجاوز التفكير والتوجيه الدولي في مجال الطفولة المبكرة المفهوم السائد الذي يجعل هدف مرحلة الطفول المبكرة تحضير الطفل وإعداده للمدرسة كليصبح المفهوم هو الرعاية التقافية المنكاملة للطفل من جميع الأبعاد الذهنية والاجتماعية والصحية عن طريق الوسائط التقافية

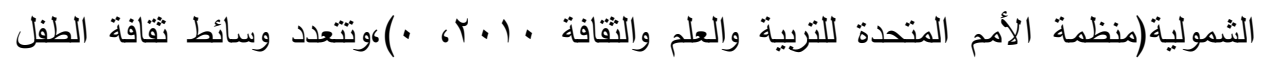
وتنتوع بدءا بالكتاب المطبوع ووصولا إلى بعض المنجزات التقنية الحديثة كالأنترنت ومرورا

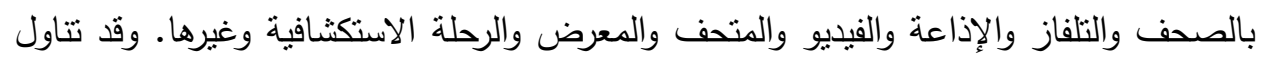

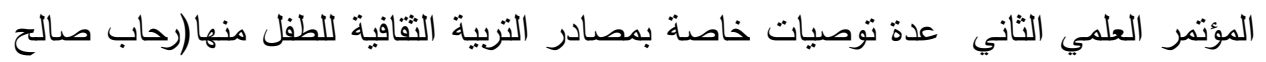

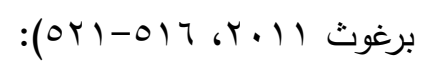

1- اعداد كتب الطفل التيتهتم بترسيخ ثقافة المجتمع الذي يعيش فيه.

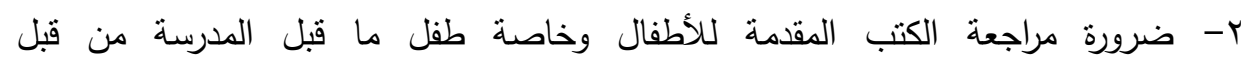
المتخصصين في مجال أدب الأطفال.

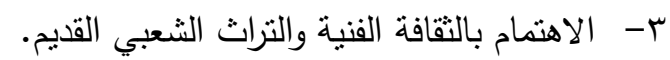
ع- استخدام الموسيقى بصورة فعالة لتنقيف الطفل. 0- تأليف القصص الموسيقية التي تدعم قيم وقواعد ومعايير ثقافة المجتمع.

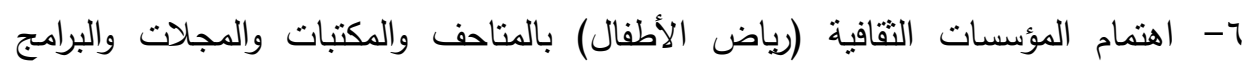
الإذاعية والتلفزيونية وبرامج الكمبيوتر الموجهة للأطفال.

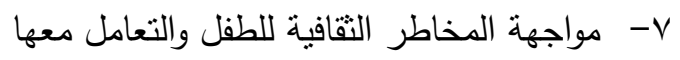
A- التتسيق والتعاون المتبادل بين الجهات المعنية بثقافة الطفل

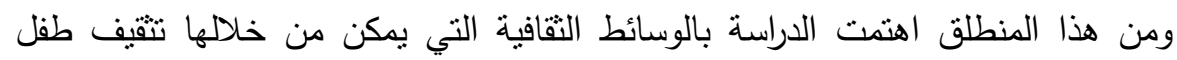

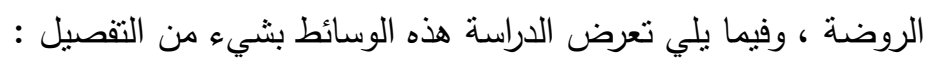
أو لا: الوسائط المطبو عة (القر ائية): إن تعويد الطفل على القراءة وإكسابه كيف ينمي مداركه مهمة مشتركة بين الأسرة

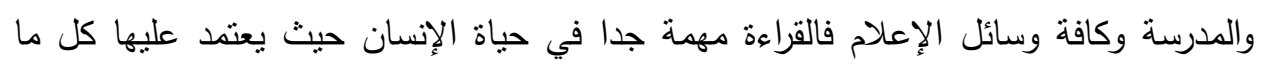

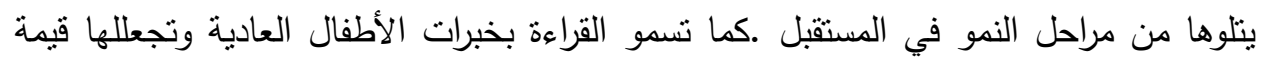
عالية، فالأطفال أينما كانوا يجربون ويختبرون كل ما يحيط بهر، وتملئهم الرغبة في أن يعرفوا

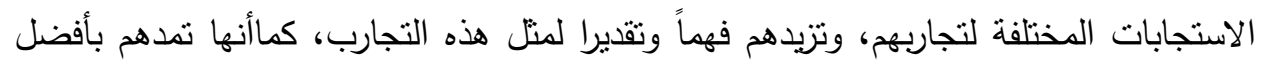
صورة للتجارب الإنسانية فتوسع دائرة خبراتهم وتعمق فهمهم للناس، ومعرفتهم حيات ونفران تغاير حياتهم 
كوإدراكهم لتتوع الخبرات الإنسانية، واحترام طرق معيشة الآخرين وطرائق تفكيرهم، كما أنها

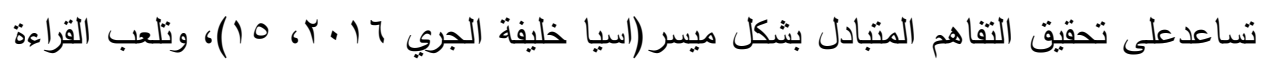

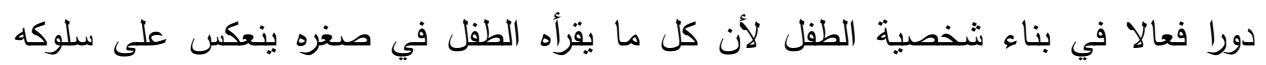

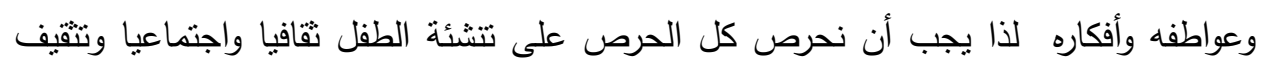

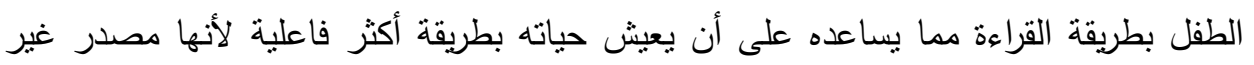

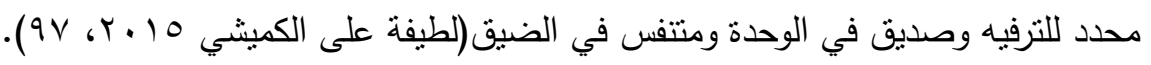
وفيما يلي عرضا موجزا للاور الذي تلعبه قصص ومجلات فئل الأطفال في التربية التقافية

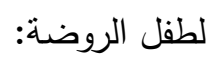

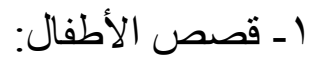

تعد القصة أبرز أنواع أدب الأطفال ،فهي تؤثر تأثيرا واسعا وعميقا على الطفل ،لأنها

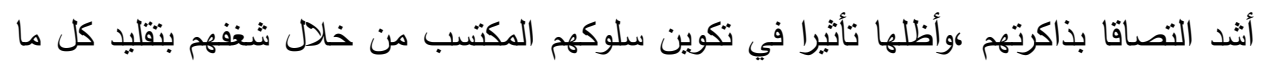

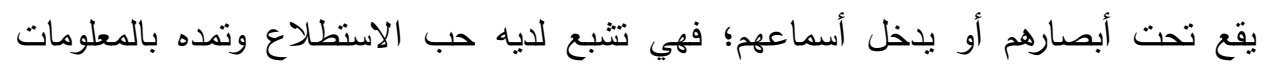
الضرورية التي تساعده على حل كثير من الشكلات واكتساب الثقة بنفسه والقدرة على التعبير لتهابه

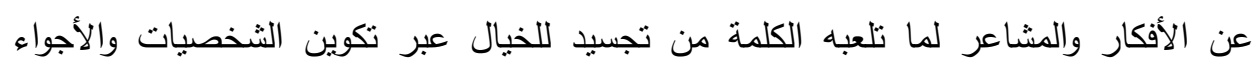

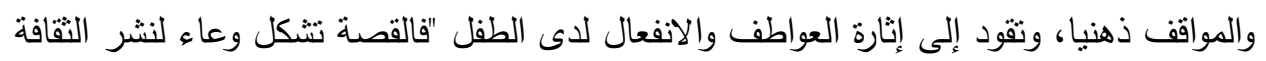
بين الأطفال لأن من القصص ما يحمل أفكار ومعلومات علمية وتاريخية وجغرافية وفنبة وأدبية ونفسية واجتماعية فضلا عما فيها من الأخيلة وتصوراتونظرات ،ودعوتهات الإنها إلى قيم واتجاهات

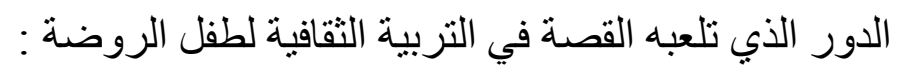

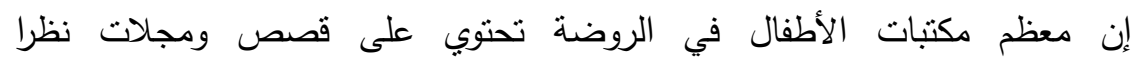
لموافقتهالتلاك المرحلة العمرية للطفل ،ويوكد ما نطرحه سعادة الأطفال مع الكتب القصصية

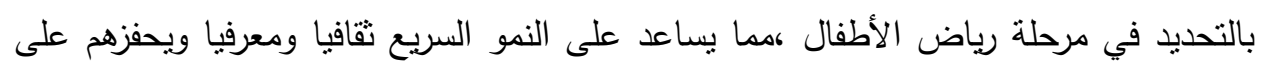

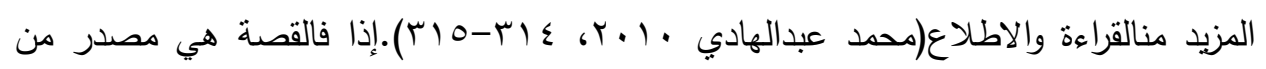
مصادر تلبية رغبة الطفل في التثقيف حيث تعمل على: 1- بتمية شخصية الطفل ونموها نموا سليما متكاملا r- تكسب الطفل المهارات المختلفة ،العقلية والعلمية . ب- بتمية الثروة اللغوية للطفل ع- المساهمة في عملية التنشئة الاجتماعية. 0- نتمية روح المسئولية لدى الطفل فملية الطئل 
צ- تتمية روح الانتماء الوطني لدى الطفل - V- نتمية القيم الإنسانية النبيلة عند الطفل.

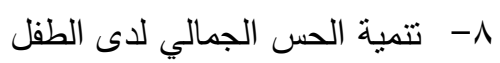

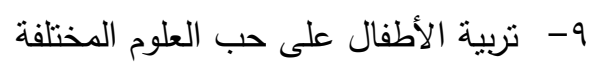

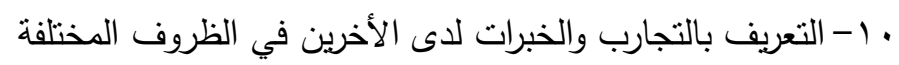

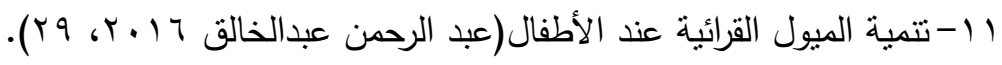
r ا-توجيه النمو الثقافي للطفل فهي تضم نماذج وأنماط للسلوك وشبكة للعلاقات بين الأفراد

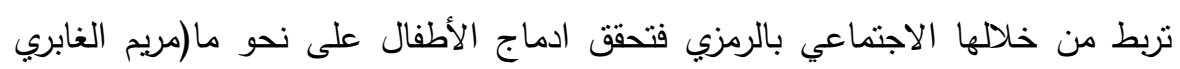

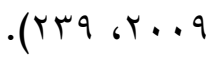

$$
\begin{aligned}
& \text { r- مجلات الأطفال : }
\end{aligned}
$$

تحنل مجلات الأطفال مكانا بارزا في انطباعات الأطفال حتى عند الذين لا يعرفون

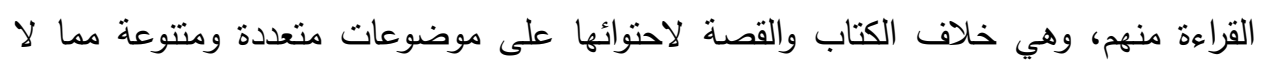

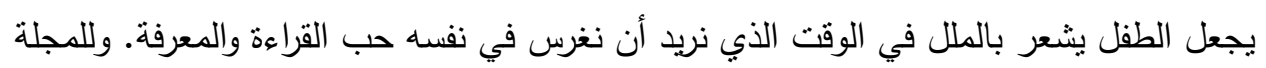

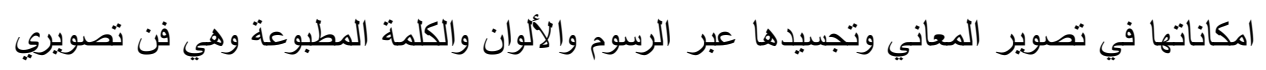

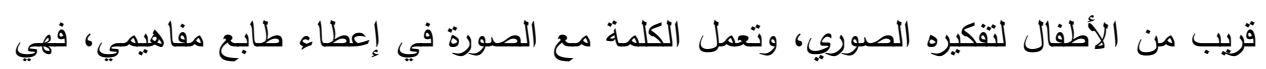

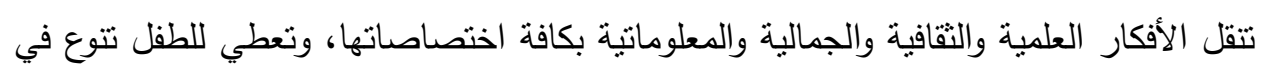

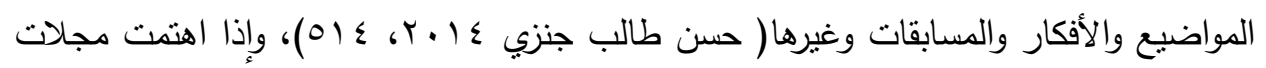

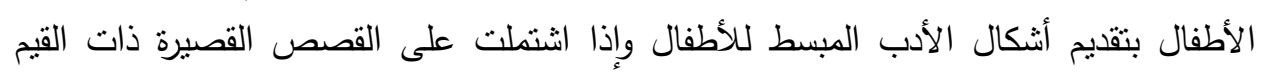
والسلوكيات السليمة؛ فإنها بذلك تكون من الوسائط الفعالة التي تجعل الطفل على دراية مستمرة بعالم الأدب والفكر والثقافة التتجددة وسوف تساعده أيضا على أن يكون قادرا جيدا طوال حياته.

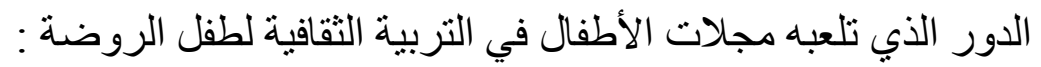
مجلات الأطفال من المصادر الهامة التي تزود الطفل بالمعرفة والثقافة والمعلومات التهات وتربطه بنقافة وقيم المجتمع الذي يعيش فيه .وهي بهذا تعمل على تكوين شخصيته ،وإثراء معارفه وثقافته، وتعلمه بما يدور في مجتمعه من أحداث، وما يتطلع إليه من آمال فهي:

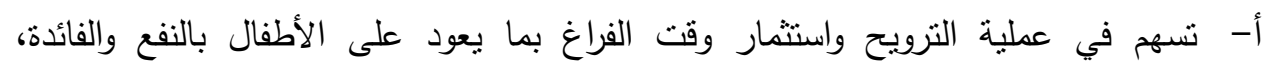

$$
\text { وتكسبهم خبرات ومهارات عديدة. }
$$


ب- تجمعه بالقراء من حوله، فالأطفال الذين يقرأون المجلة يتصلون بالعالم من خلالها، ويتصل

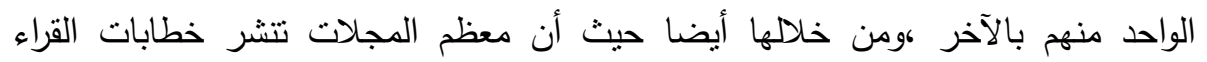

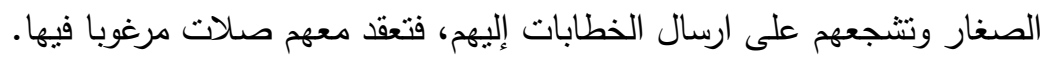

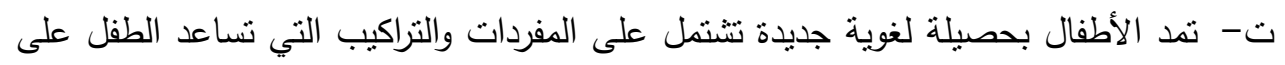
التعبير عن نفسه وتزيد من إمكاناته اللغوية .

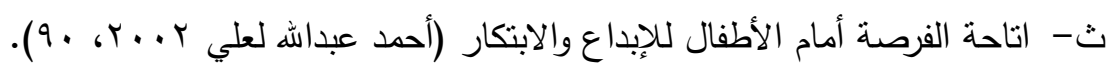
ثنانيا: الوسائط المسمو عة:

وهي الوسائط المتمثلة في الراديو والقنوات الإخبارية التي ينم نقل المعلومات والمعارف والخبرات من خلالها بطريقة شفهية ومسموعة فقط وسوف تنتاول الدراسة البرامج الإذاعية كأحد هذه الوسائط مع توضيح دورها في التربية النقافية لطفل الروضة بشيء من الإيجاز في النقاط الثالية:

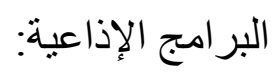

يعتقد البعض أن انعدام الصورة في البرامج الإذاعية المسموعة ،قد يمثل أحد أوجه

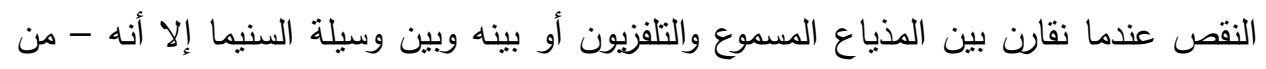
ناحية أخرى - يمكننا أن نعتبر ذلك إحدى الميزات التي يتفوق بها المذياع عن الوسائل السمعية

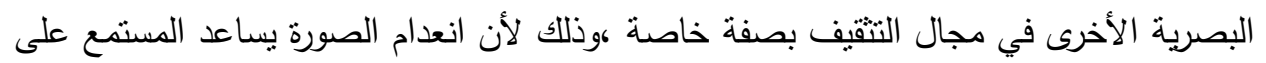
تركيز انتباهه على الكلمة وعلى النص مما يؤدي إلى زيادة وتعمق استفادته في تحصيله في هذا

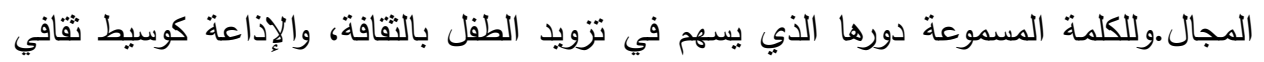

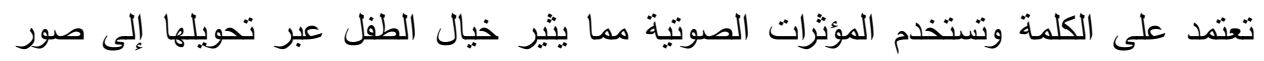
صوتية نابضة الدور الذي تلعبه البر امج الإذاعية في التربية التقافية لطفل الروضة :

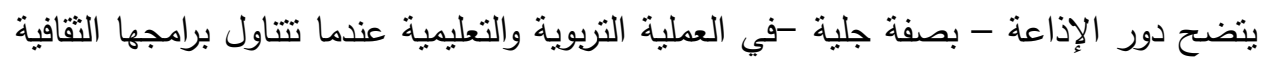
بأسلوب منطور يجعل الحقائق العمية سهلة التصور بفضل استخدامها طرقا مختلفة عن تلإلك

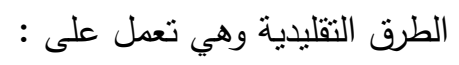
أ- تتقيف الطفل من خلال استخدام وسيلة سمعية ينجذب إليها إذا كانت تحتوي على مواد مفيدة تلفت الانتباه وتدعوالطفل إلى الاستماع والمتابعة

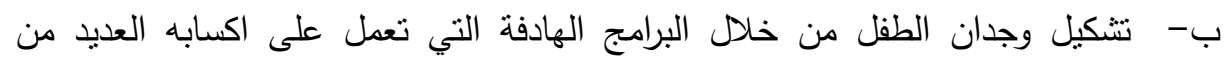
الاتجاهات والقيم المرغوب فيها 
ت- ت تدريب الطفل على التأمل ومهارة التعبير وتتمية ملكة النقد لديه حيث تغرس في نفسه

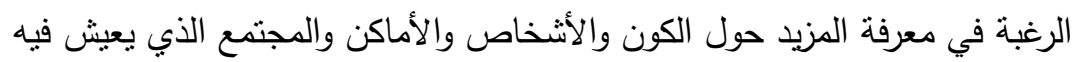

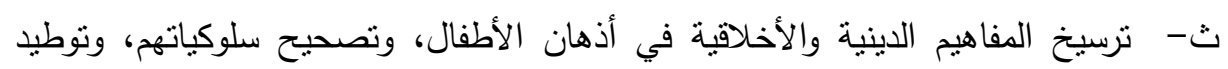

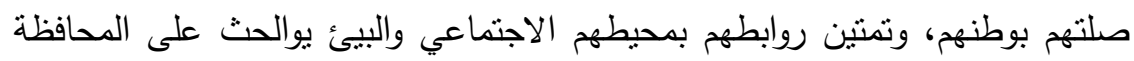
عليه. ج- - وبإمكان الإذاعة أن تؤدي دورها التربوي عندما تتيح للأطفال الفرصة للمساهمة في

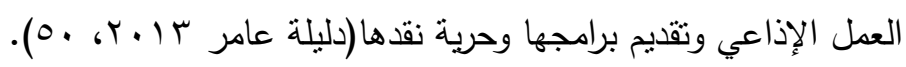
ح- - تقديم المعلومات المبسطة حول الموضوعات والحقائق التي تهم الطفل وكذلك الأحداث

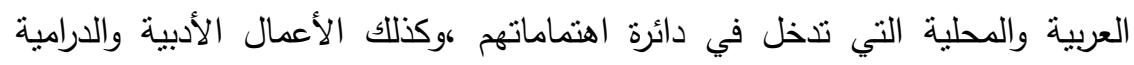

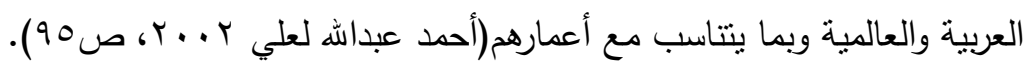
ثنالثا: الوسائط المسمو عة و المرئية: وتتتنل في الهواتف الذكية وشبكة الانترنت وأجهزة التلفاز وأثرطة الفيديو والسينما التي

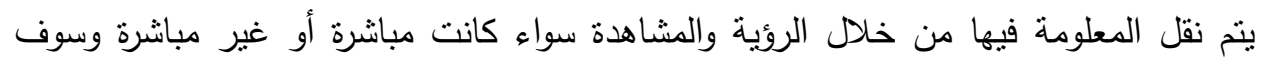

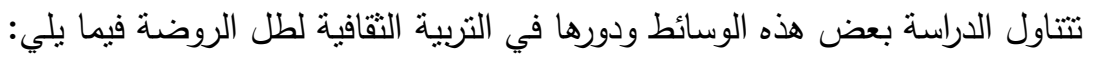
1 - التلفزيون:

يعتبر من أهم وسائط نتقيف الطفل وأكثرها جاذبية وامتاعا له في مرحلة رياض الأطفال كإذ يجمع بين العديد من المؤثرات كالصوت والصورة واللون والحركة ،ولعل طبيعة الطفل المولعة

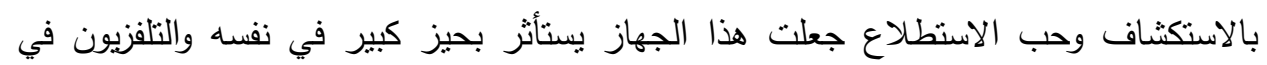

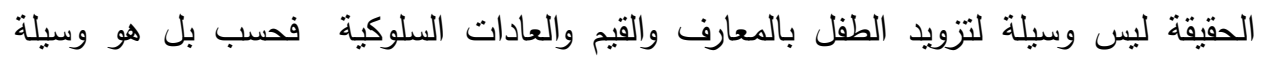
لتكوين وعيه الثقافي الإنساني وهو يسهم اسهاما أساسيا في بناءه التربوي عموما ،ذلك إن مكناه من البرامج المفيدة والمناسبة كبرامج التعليم المبسط وموضوعات الطبيعة والحيوان وأفلام

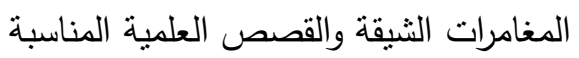
الدور الذي تلعبه البر امج التلفزيونية في التربية التقافية لطفل الروضة التبة : يتميز التلفزيون كوسيط تربوي نقافي بأن له جاذبية كترجع إلى أنه يعرض كلئ كل ما لها هو

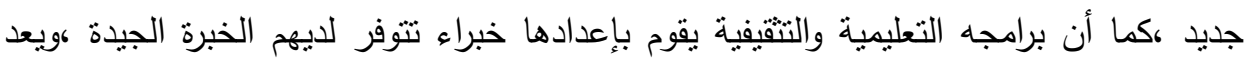

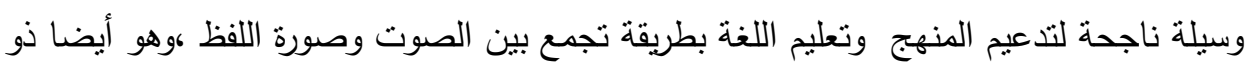

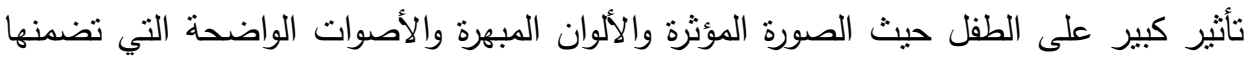

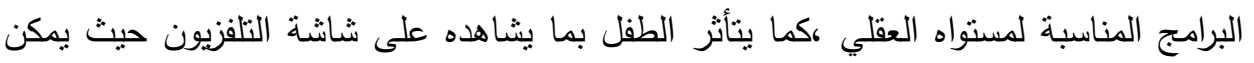


تعديل ميوله واتجاهاته وميوله من السلبية إلى الإيجابية ولذك أصبح التلفزيون موضع اهتمام

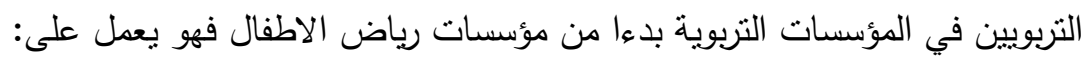
أ- تتمية الجانب الاجتماعي في الطفل ومثاركة الاخرين وتبادل أطراف الحديث معهم فيما يتم مشاهدته. ب- صقل وجدان الطفل وأحاسيسه بما يغمره من جو الترفيه والتسلية واستماع الموسيقى والايقاع الجميل الذي يدرب حواسه من صغره على الإصغاء والمتابعة والربط والتحليل .

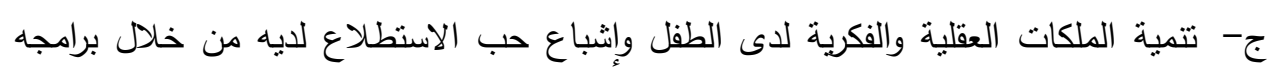
الثقافية . د- - إثارة الخيال الواسع لدى الطفل من خلال ما يقدمه من صور وموسيقى ومسلسلات وألوان

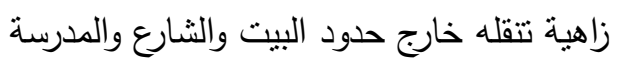

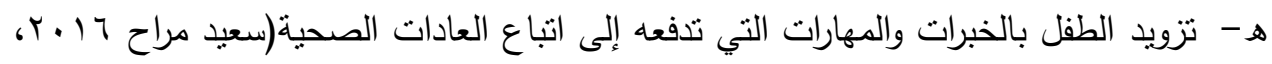
بـ الأفلام السينمائية و الرسوم المتحركة:

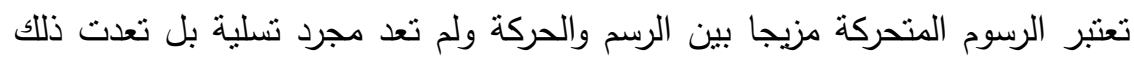
إلى أهداف ثقافية أكبر • ويميز هذه الرسوم المتحركة عن الأثكال السينمائية الأخرى (الفيلم

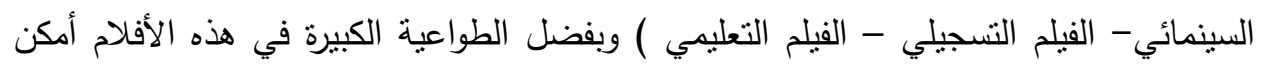

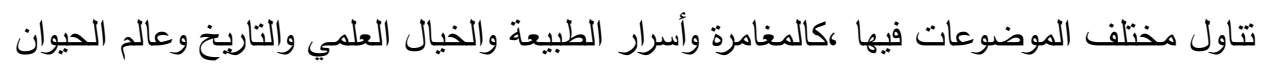

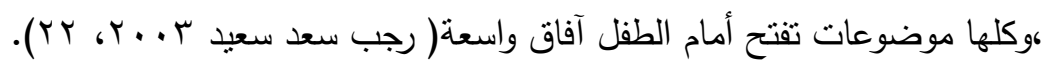

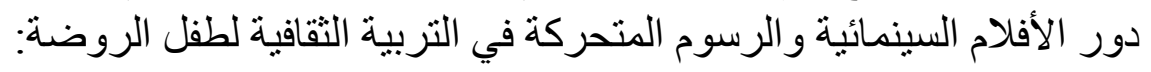
للأفلام السينمائية والرسوم المتحركة دور هام في التربية الثقافية للطفل حيث يعتبران

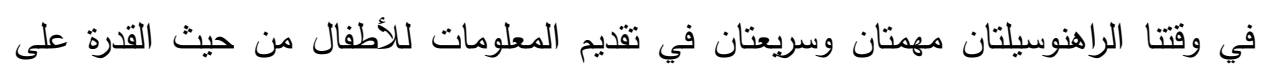

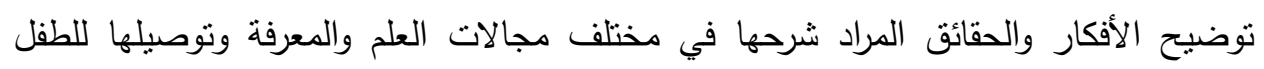
بطريقة سهلة ميسرةوبأقل وقت ممكن من ناحية ،ومن ناحية أخرى فإن الطفل عن طريقهما

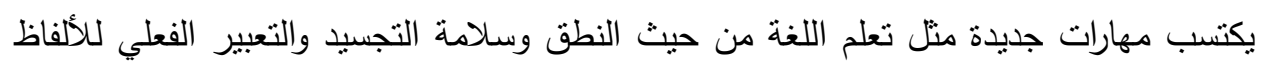
،وانثباع رغبة الطفل الفطرية في التمثيل والحركة والتقليد ،كما تلعبان دورا هاما في مجال نقال نقافة الطفل. ويشير الأستاذ يعقوب الثاروني إلى أهمية الدور الذي تلعبه تلك الأفلام من خلال العبارات 


\section{الوسائط الثقافية في رياض الأطفال \\ أ.د/ محمد أبو النصر حسن أ.د/ أحمد خيري محمد أ/ نعمة علي محمد حفوضة}

أ- اكتساب الخبرات المتتوعة وتتميتها من خلال سينما الأطفال .

ب- تتمية الثقة في الطفل ،وإثارة الاهتمام مما يساعد على تتمية الملكات الإبداعية والطاقات الخلاقة .

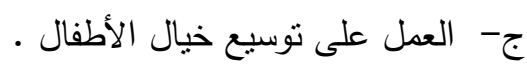

د- ادراك الأطفال للمنل العليا المجسدة أكثر من ادراكهم للاعوات الأخلاقية المجردة من خلال سينما الأطفال . - س الاطفال

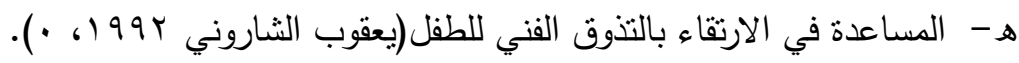
ومن هنا تلعب السينما دورا ايجابيا في التربية الثقافية للطفل ،حيث تعتبر احدى الوسائل التي يكتثف بها الطفل العالم الذي يعشه ،ولأن السينما لا تعتمد فقط على الفكرة ،ولكنها

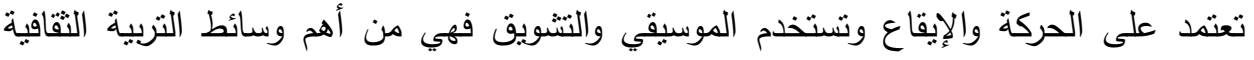
للطفل ،بالإضافة إلى أنه من خلال السينما يمكن تقديم الكثير من المعلومات للطفل وكذلك يمكن

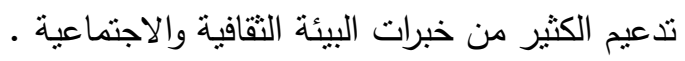

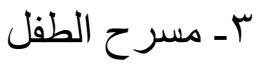

يعتبر المسرح وسيطا مهما من وسائط ثقافة الطفل ،حيث يكتسب الطفل خبرات متعددة

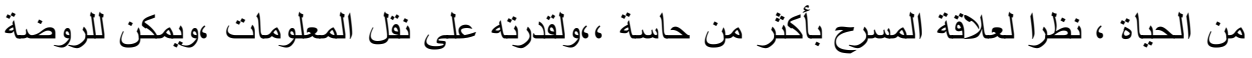

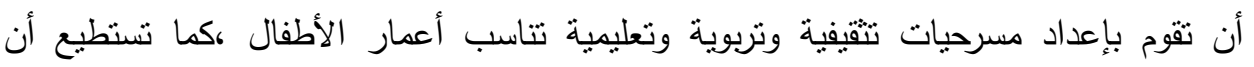

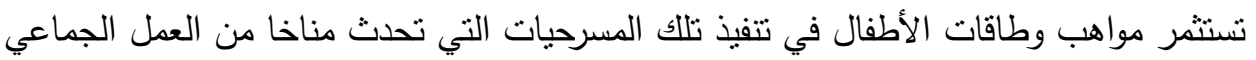
والتعاون بين الأطفال.

ويعتبر مسرح العرائس من أنسب أنواع المسرح لطفل الروضة فهو قريب من الصغار

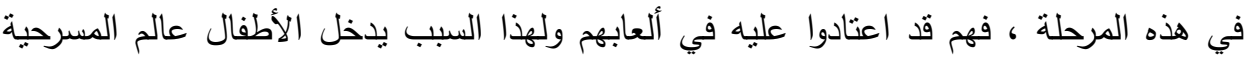

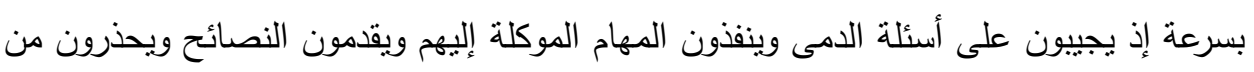
الخطر ويحاولون تقديم المساعدة إلى أبطال المسرحية ،ولكن لا يمكن النظر إليه كتسلية لا أكثر الثرام

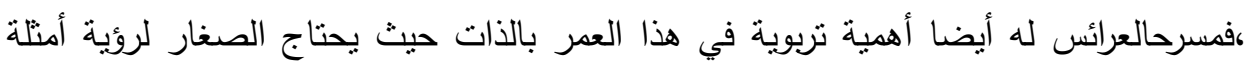

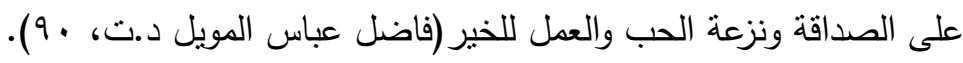

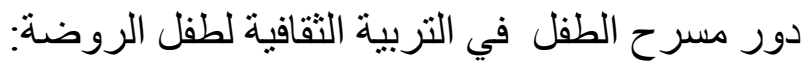
يعمل مسرح الطفل على تطوير مؤهلات الطفل وقدراته وميوله واهتماماته الابداعية كما يعمل على تطوير المجال الذهني وحب الاستطلاع والقدرة على اتخاذ القرارات المستقلة وطرح التساؤلات والبحث عن الردود واستقصاء الحلول وتتمية الذوق الجمالي عبر فاعلية المشاركة 
بجميع حواس الطفل عبر النلقي المباشر الممنل بالحضور الذهني. كما يسنطيع مسرح الطفل أن

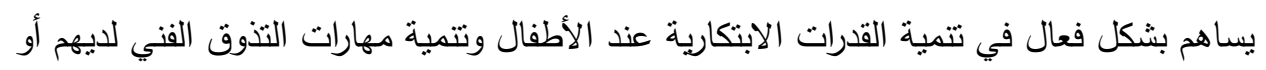
على الأقل يساعد الأطفال على أن يتعلموا كيف يفكرون وكيف يتعلمون وكيف يتذوقون

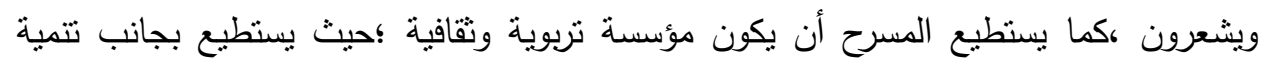

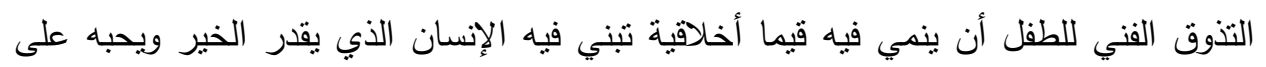
أسس دينية اجتماعية وإنسانية ،كما بسعى إلى تزويده بتجارب البشرية التي تطور وعيه وطريقة

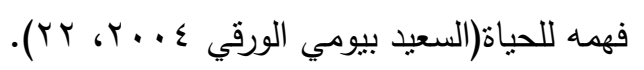

ويمكن تلخيص ما يسنطيع أن يقدمه العمل المسرحي لأطفالنا ونحن نتحدث عن التربية

النقافية بأساليبها المختلفة للطفل لدى الأطفال في النقاط التالية: أ- تتمية مدارك الطفل وتوسيع ثقافته ،ويدربه على ضبط انفعالاته وتفريغ شحناته العاطفية

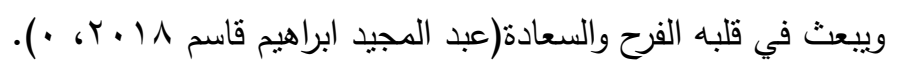

ب- ت تمية الثقة بالنفس.

ج- الاستمتاع للأطفال الموهوبين للمسرحية وكذلك الأطفال المشاهدين(رضا مسعد وأحمد

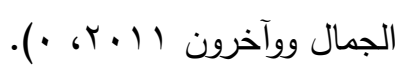

د- يمثل مسرح الطفل القيمة التربوية والثقافية والأخلاقية لأنه يبحث في تأسيس أهداف

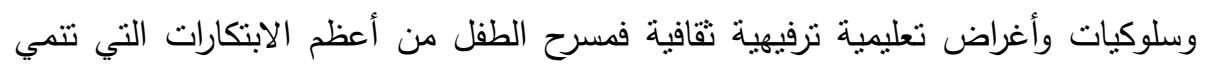

$$
\text { عقلية الطفل(عدنان خلف ساهي } 9 \text {. . r، (1). }
$$

ويجب أن يتضمن العمل المسرحي المخصص للطفل في مرحلة رياض الأطفال القيم العربية الأصيلة ،وأن يشارك الأطفال جميعهم في النشاط المسرحي ،إما عن طريق التمثيل مباشرة أو عن طريق الإسهام في الفنون المساعدة أو عن طريق مشاهدته ومثابعة خطواته ،وألا يكون العمل المسرحي المخصص للطفل طويلا بحيث لا يرهق الطفل ،كما ينبغي أن يكون

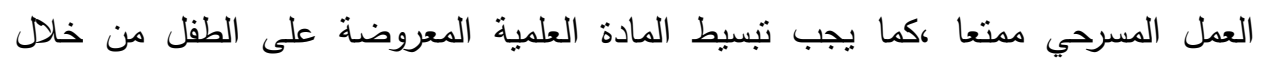
المسرحية وتضمينها الخبرات المناسبة لمستوى طفل الروضة العقلي والزمني وأن تتضمن علاجا

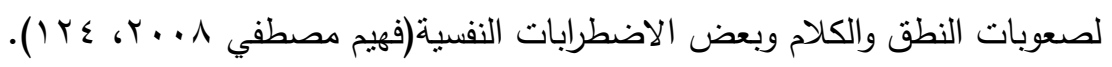
رابعا :الأنشطة الترويحية:

عرفت دراسة عمر زهير الأنشطة النرويحية أنها" جملة من النشاطات التي يقوم بها الطفل لذاته ،تحدث في وقت الفراغ كنتيجة لرغبة داخلية بهدف التسلية والراحة والاندماج الأنه

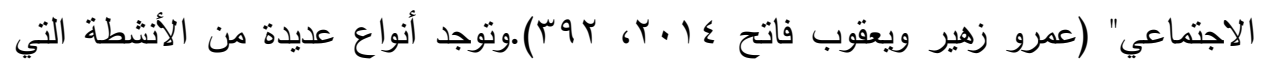


يمكن أن يمارسها الطفل داخل رياض الأطفال وتعالج مختلف المشكلات السلوكية والعضلية

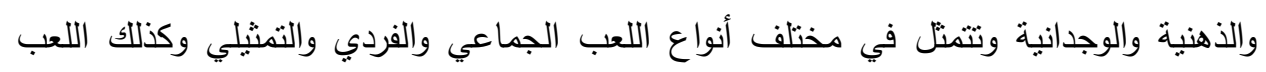

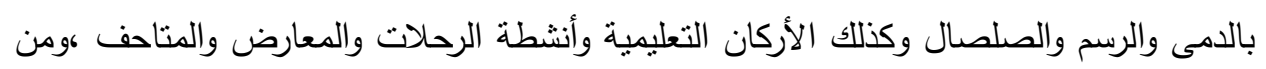

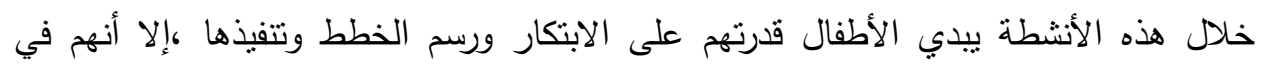

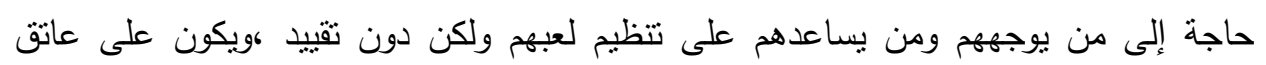

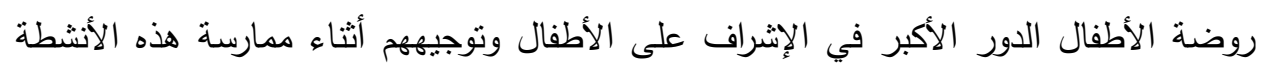
،وسوف نتناول بعض هذه الأنشطة النرويحية بثيء من التفصيل في العناصر الأثية:

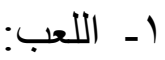

اللعب هو عالم المثيرات والدوافع الغني بالخيال ،وهو نشاط بستخدمه الطفل بغرض الترفيه وإضافة البهجة والسرور ،وهو ضروري وطبيعي في حياة الطفل ،حيث يقضى فيه الطفل

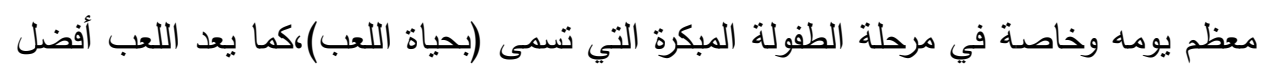
الطرق لإكساب الطفل ثقافة وخبرات المتمع وتسنطيع المعلمة أن تستغل المظاهر الطبيعية باعتبارها كتابا مفتوحا للطفل بما فيه من مادة غزيرة. وتقف أساليب التربية المفتوحة القائمة على مبدأ اللعب والنشاط التقافي جنبا مع التربية

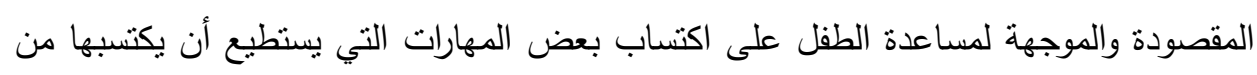

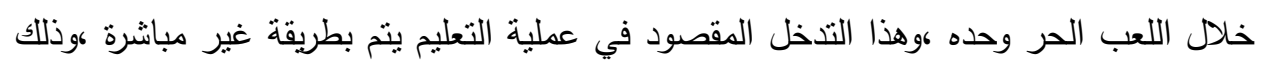

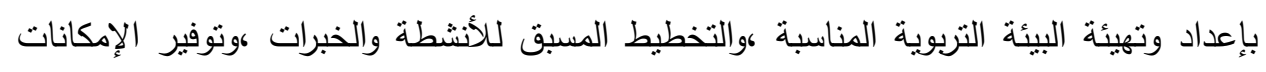

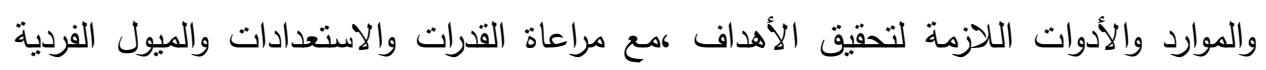

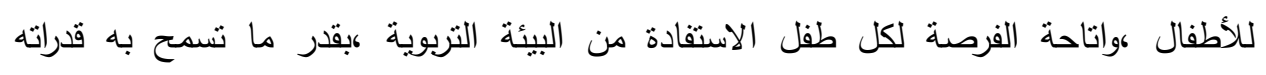

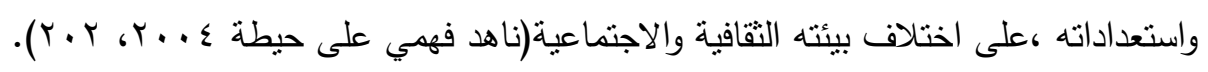

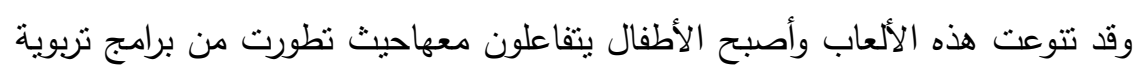

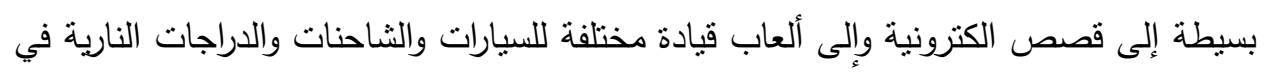

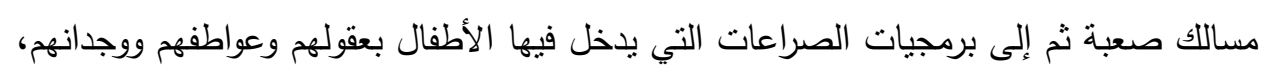

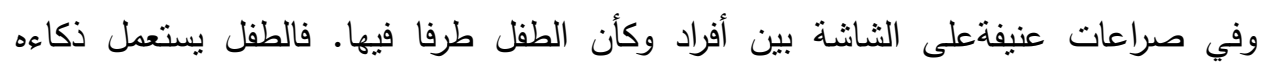

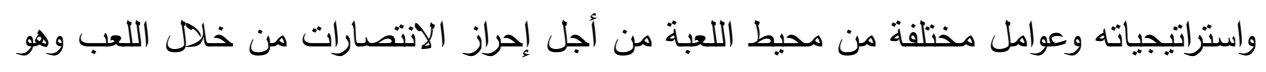

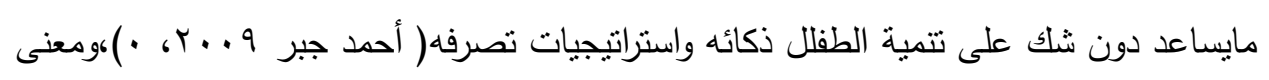
هذا أنّ هذه الألعاب تسهم بتطوير نشاط الطفل في اللعب، وتزيد من مهاراته، وتتشيط مجالات 
تقكيره، وتعمل على اثراء مخيلته وتتشيطها باتجاه أوسع،وتدفع قدراته إلى النمو والإدراك الواسع

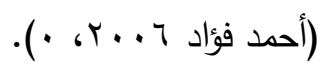

دور أنشطة اللعب في التربية الثقافية لطفل الروضة:

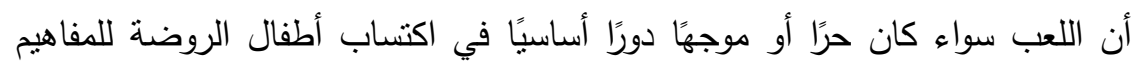

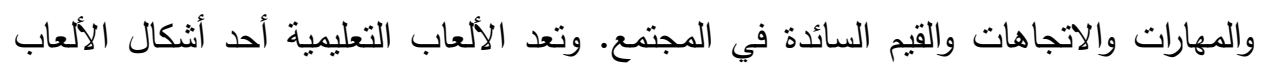
الموجهة والمقصودة التي تحقق أهداف تربوية محددة في جو من المتعة والبهجة، وتجمع أحيانًا

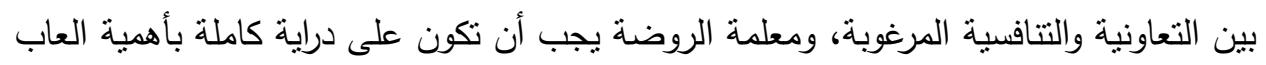

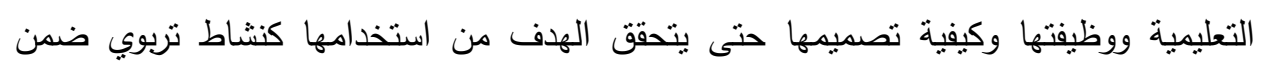
أنثطة المنهج وفيما يلي عرض الدور الذي تلعبه الألعاب التعليمية في التربية الثقافية للطفل أ- تناعد على إحداث تفاعل الفرد مع عناصر البيئة لغرض التعلم وإنماء الثخصية والسلوك.

$$
\text { ب- تقرب المفاهيم وتساعد في إدراك معاني الأشياء }
$$

ج- تعد أداه فعالة في تفريد التعلم وتتظيمه لمواجهة الفروق الفردية وتعلم الأطفال وفقا لإمكاناتهم وقدراتهم تعدمان

د- - تعمل الألعاب على تتشيط القدرات العقلية وتحسن الموهبة الإبداعية لدى الأطفال.

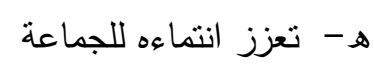

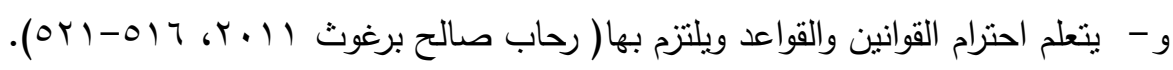

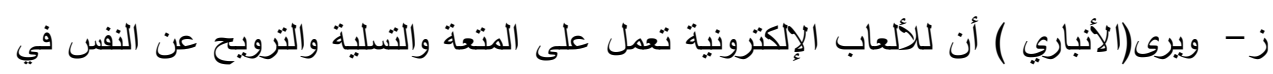

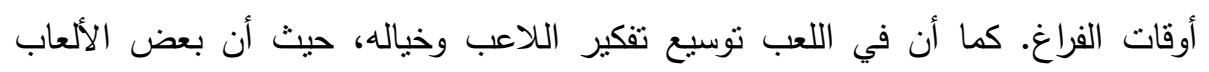
تحمل ألغازا تُساعد في تتمية العقل والبديهة وهي وسيلة منافسة بين الأصدقاء من خلال

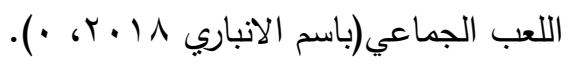

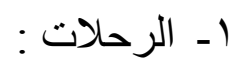

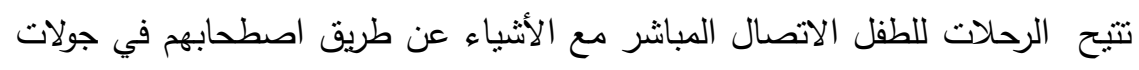

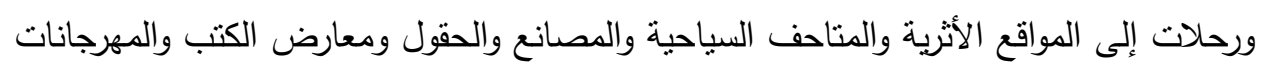
الأدبية والترفيهية والأسواق؛ كل ذلك يوقظ عند الطفل مشاعر كثيرة وعميقة تسهم في نشر التقافة

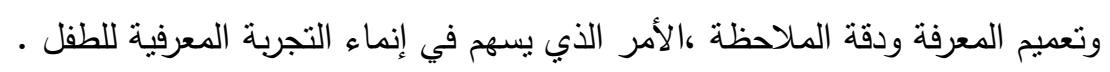

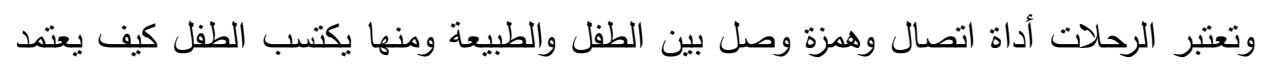

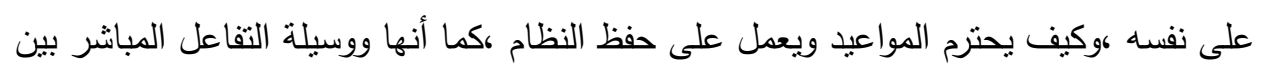


الطفل والبيئة المحبطة، ووسيلة لاكتساب الخبرات المباشرة ،نتيجة احتكاكه بالبيئة(منى محمود

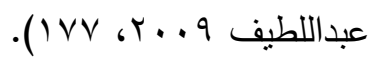

دور الرحلات في التربية الثقافية لطفل الروضية: تعد الرحلات والزيارات من أهم الخبرات التربوية المباشرة التي تنتح لأطفال التبال الروضة فرصًا متعددة للتفاعل المباشر مع البيئة الاجتماعية والمادية التي تحيط بهم وذللك من خلال: أ- ت توفر خبرات مباشرة حية.

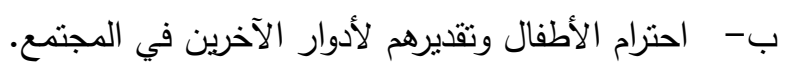
ج- احترام الأطفال للملكيات العامة والخاصة.

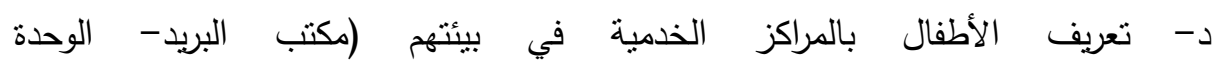

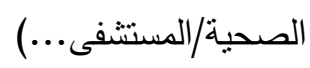
هـ - - اكتساب المفاهيم والحقائق.

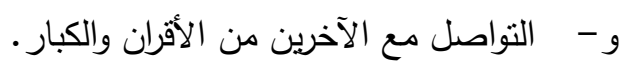

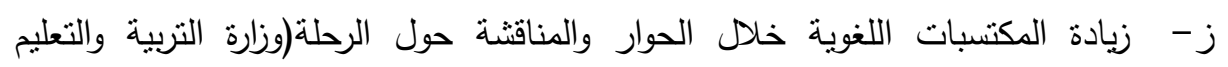

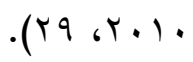

وعلينا أن نترك الطفل يتحدث عما شاهده فتتشأ لايه شروة معرفية وتتكون بذور مختلفة

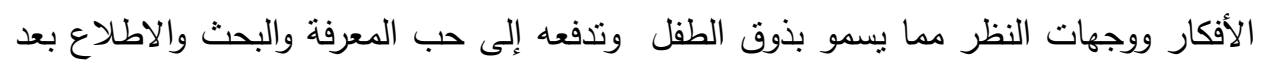
ذلك. ا ـ مر اكز التعلم /الأركان التعليمية: يؤثر تتظيم بيئة الصف في نمو مشاعر أطفال الروضة وتنفكيرهم؛ فيزيد من احترامهج

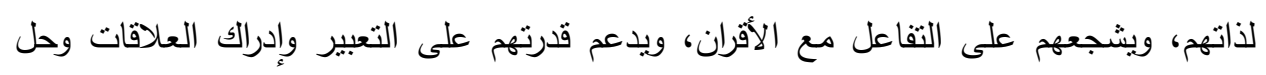
المشكلات، ويحفز لديهم الرغبة في الاكتثاف والابتكار ، وتتظيم القاعة وفقًا لنظام الأركان التعليمية يتيح الفرص لتحقيق النمو المتكامل المنوازن للطفل، إلا أن ذلك يتطلب أن الن تكون

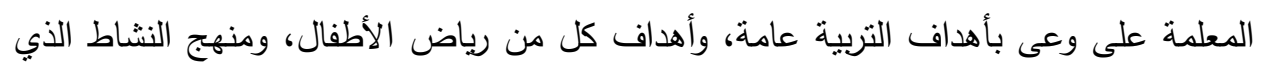

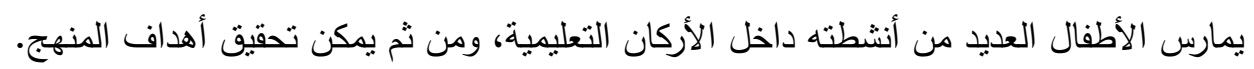

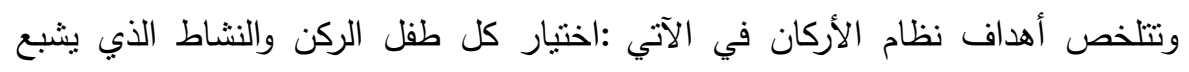

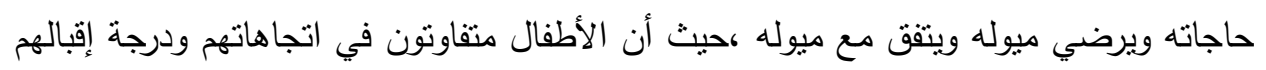

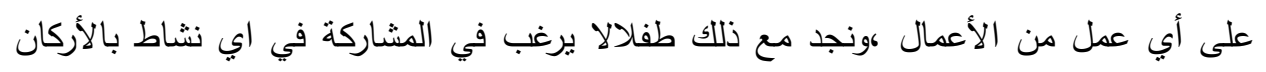

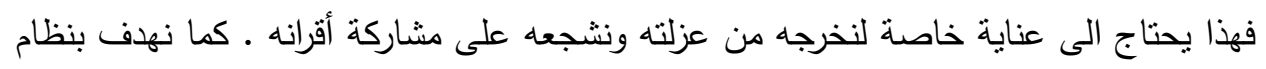


الأركان إلى أن يواجه الأطفال المواقف الجديدة بثقة، تتمية الضبط الذاتي والاستقلال والثعور

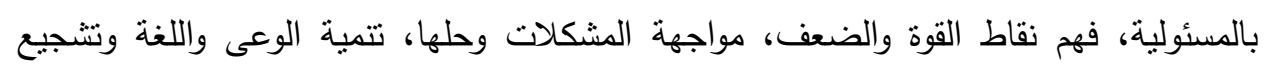

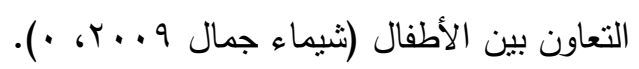

دور مر اكز التعلم في التربية الثقافية لطفل الروضة: أكدت الدكتورة أمل خلف " عليأن الأركان التعليمية (مراكز التعلم)هي جزء مهم من العملية

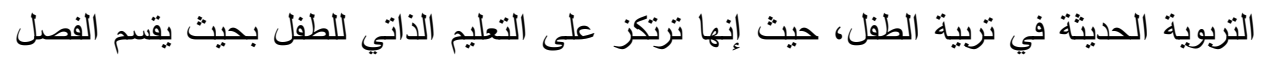

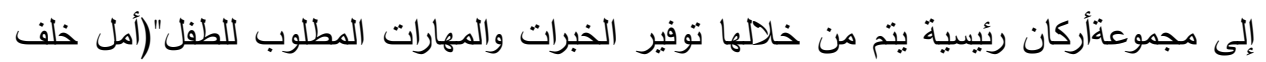

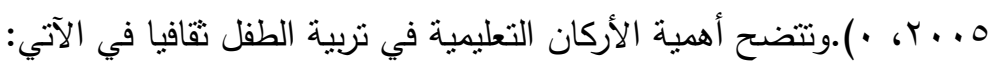
أ- مراعاتها للخصائص النمائية للطفل

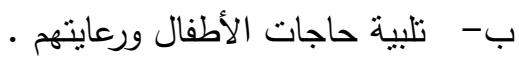
ج- إعطاء الطفل حرية الاختيار ودفعه للتعلم الافضل . د- مساعدة الاطفال على الاتصال والتواصل واكتساب الكثير من القيم والاتجاهات .

$$
\begin{aligned}
& \text { هـ - مساعدة الطفل على اكتساب مهارة التعلم الذاتي } \\
& \text { و - إسهامها في معالجة السلوك غير المرغوب فيه . } \\
& \text { ز - توفير الراحة والطمأنينة }
\end{aligned}
$$

ح- تحقيق كافة الأهداف التي تتعلق بتتمية قدرات الطفل المتكاملة والمتوازنة والثشاملة(موقع

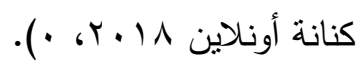

تتاولت هذه الدراسة بعض الوسائط الثقافية في مؤسسات رياض الأطفال وأوضحت الون

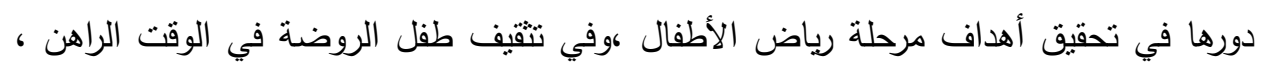

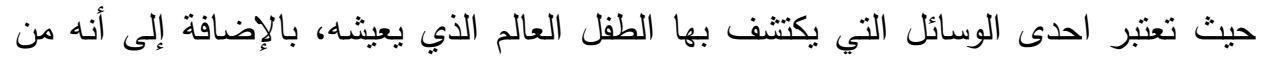
خلال تلك الوسائط يمكن تقديم الكثير من المعلومات للطفل وكذللك بمك نتدعيم الكثير من خبرات البيئة الثقافية والاجتماعية وعرضت الدراسة أربعة أنواع من هذه الوسائط هي:الوسائط

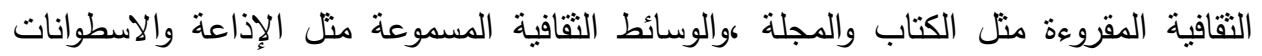
وغيرها والوسائط الثقافية المرئية كالتلفزيون والمسرح والأفلام السينمائية ، وكذلك الأنشطة

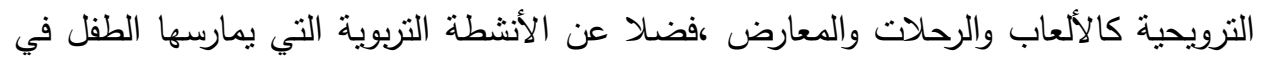

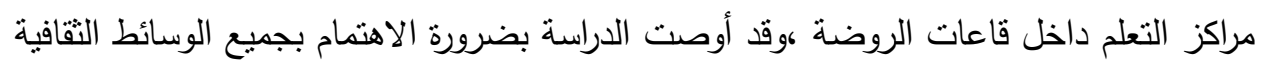
في رياض الأطفال لمواجهة التحديات النقافية الراهنة. 
أحمد جبر ـ(2009) ـ طفلك والألعاب الإلكترونية مزايا وأخطار ركن الطفل." مجلة

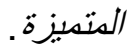
حسن طالب جنزي.(2014). "ثقافة الطفل بين الهوية والغزو الثقافي." مجلة الكلية

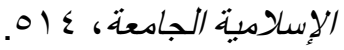
رجب سعد سعيد. (2003)."الثقافة الغائبة." مجلة خطوة، ب r. رحاب صالح برغوث.(2011). "مجلة الطفولة والتربية." الألعاب التعلية ودورها في

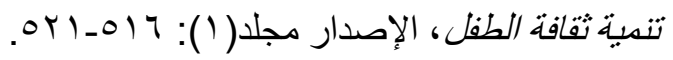
أحمد عبداله لعلي.(2002). الطفل والتربية الثقافية رؤية مستقبلية للقرن الحادي والعشرين.

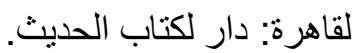
أحمد فؤاد. (2006). سلامة اطفالنا و الاستخدام الخاطي للكمبيوتر ." مجلة خطوة ، الإصدار

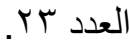

اسيا خليفةالجري.(2016). "التدريب على القر اءة و أثرها في توسيع مدارك وثقافة الطفل." مجلة القراءة والدعرفة: الجري: 10. السعيد بيومي الورقي. (2004)."مسرح الطفل والتنشئة الثقافية." مجلة خطوة، الإصدار

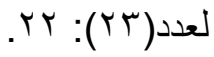
أمل خلف.(2005). مدخل إلى رياض الأطفال. القاهرة: عالم الكتب.

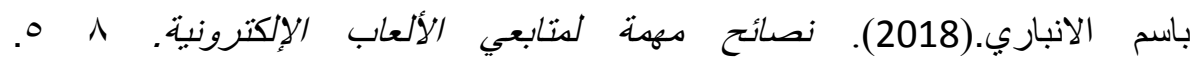
.http://alexmedia.forumsmotions.com/t150-topic

دليلة عامر .(2013). "البعد التربوي و التعليمي في البرامج الموجهة للطفة الطفل دراسة تحليلة

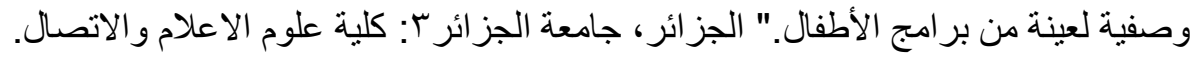
0 .

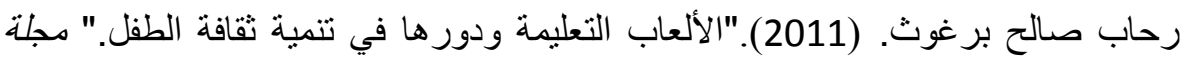

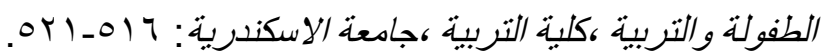

رضا مسعد وأحمد الجمال ووآخرون.(2011). "دور الأنشطة الثقافية في تتمية انتماء الطفل ل كروضته." مجلة كلبة التربية. 
سعيد مراح.(2016). "لتلفزيون و التحصيل الدراسي للطفل أبعاد التأثير وحدود التغيير."

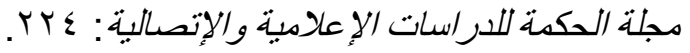
شيماء جمال.(2009). الأركان التعلبية لرياض الأطفال. https://m.youm7.com/story/2009/8/9/\%D8\%A8\%D8\%A7\%D9\%84\%D 8\%B5\%D9\%88\%D8\%B1\%D8\%A7\%D9\%84\%D8\%A3\%D8\%B1\%D9\%83\%D8\%A7\% .$(Y \cdot) \wedge .0 \wedge$ عبد الرحمن عبدالخالق.(2016). "دور قصص الأطفال في تتمية الطفل." مجلة خطوة،

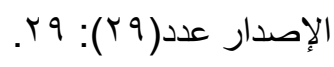
عبد المجيد ابر اهيم قاسم.(2018). "وسائط ثقافة الطفل وخصائصها." مجلة الوعي الثبابي. 0 ديسمبر. http//:alwaeialshababy.com. عدنان خلف ساهي. "و اقع الموسيقى و الغناء في عروض مسرح الطفل العر اقي المعاصر."

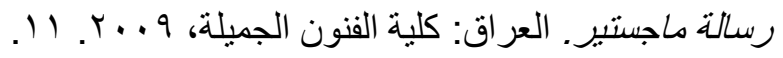

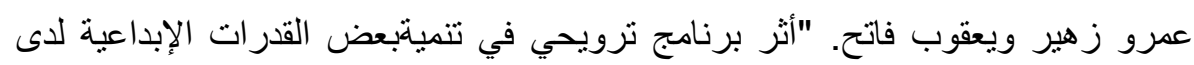

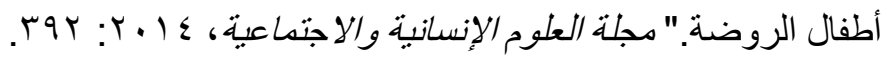

فاضل عباس المويل. مسارح التربية في الكويت كوسيلة تربوية فنية لصغار الثناميذ. ردمك

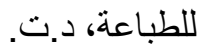

فهيم مصطفي. الطفل والخدمات الثقافية رؤية عصرية لتثقيف الطفل. القاهرة: الدار

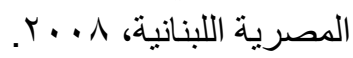

لطيفة على الكميشي. "القراءة وتتمية ثقافة الطفل." مؤتمر أعمال الملتقى الدولي. البلبيدةالجز ائر: مركز جيل البحث العلمي، 10 ـ. Y.

محمد عبدالهادي. "مكتبات الأطفال ودور ها في تمية ثقافة النشء." مجلة مكتبة الملك فهر

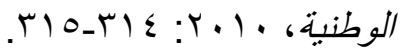

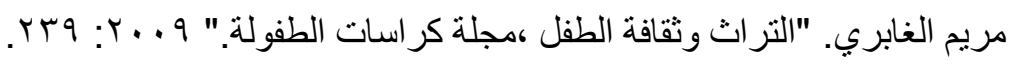
منظمة الأمم المتحدة للتربية والعلم و الثقافة ـ مشاريع مبتكرة ودروس وتحسيات في تربية

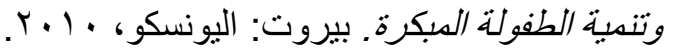
منى محمود عبداللطيف.(2018). التربيةو الدجتمع. الرياض: دار الزهراء، 9 . . r. 


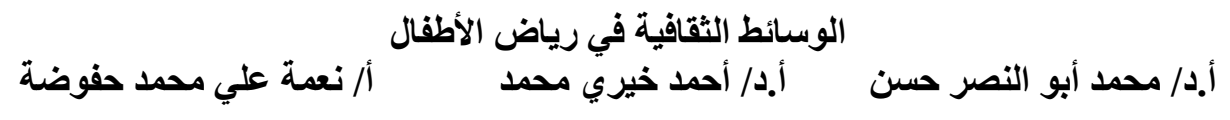

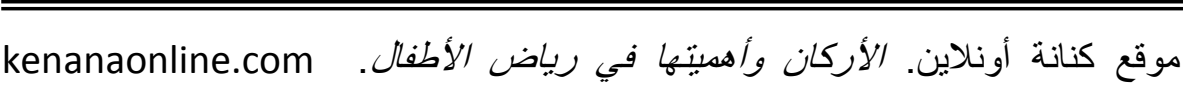

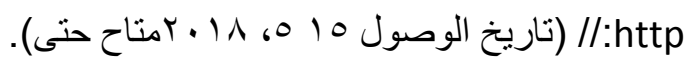

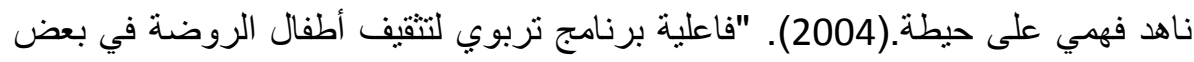

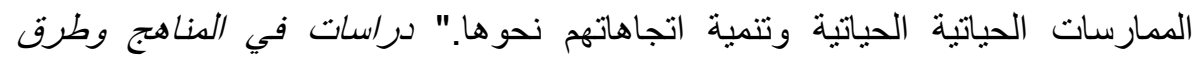
التدريس. جامعة القاهرة،. Y.r.

وزارة التربية والتعليم.(2010). معلمة الروضة معابير ومدارسات. جمهورية مصر

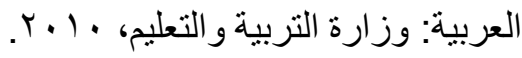

يعقوب الثاروني.(1992). "المسرح و السينما الموجهان للطفل العربي." مقال في كتاب :ثقافة الطفل العربي،. 